\title{
Attitude and Perceived Behavioral Control Toward Reducing water pipe Use in Women
}

Lale Hasani

Assistant Professor of Health Education and Promotion, Mother and Child Welfare Research Center, Hormozgan University of Medical Sciences, Bandar Abbas, Iran

Teamur Aghamolaei

Professor of Health Education and Promotion, Social Determinants in Health Promotion Research Center, Hormozgan University of Medical Sciences, Bandar Abbas, Iran

Roghayeh Ezati rad

* PhD Candidate of Health Education \& Promotion, cardiovascular research center, Hormozgan University of Medical Sciences, Bandar Abbas, Iran. (Corresponding Author).

Email: Ezati_rad@yahoo.com

Khadije Ahmadzadeh

PhD Candidate of Medical Library and Information Sciences. School of Management and Medical Information Science, Isfahan University of Medical Sciences, Isfahan, Iran.

Amin Ghanbar nejad

PhD Candidate of Biostatistics, Social Determinants in Health Promotion Research Center, Hormozgan University of Medical Sciences, Bandar Abbas, Iran.

Received: 2019/09/9

Accepted: 2020/07/21

Doi: 10.29252/ijhehp.8.4.255

\section{ABSTRACT}

Background and Objective: Hookah smoking is on the rise significantly among families, young people, and especially women and it is regarded as a new challenge for public health. This research aims to investigate the variables of attitude and perceived behavioral control in reducing smoking hookah in women over 15 years in Bandar Abbas.

Materials and Methods: In this quasi-experimental study, 128 women over 15 years who had at least once hookah smoking at day were selected using a multistage stratified cluster survey design. They have classified in two groups of case and control groups (64 people per group). Data were collected using a validated and reliable questionnaire based on the theory of planned behavior constructs and demographic information. Participants filled out questionnaires before the intervention. The educational intervention was conducted for the experimental group in 4 sessions based on pre-test results. 2 months after the intervention, both groups were evaluated and filled out the questionnaire. Finally, their information was assessed using independent paired t-test, t-test, and chi-square test.

Results: The results showed that there is significant difference in the attitude score and perceived behavioral control in the intervention group after the educational intervention and the educational intervention was effective $(P<0.05)$. In addition, the frequency of hookah smoking among women in the intervention group compared to controls has significantly decreased after the intervention $(P<0.05)$.

Conclusion: The implementation of a curriculum based on the theory of planned behavior suggests the positive effect of the educational program on attitude and perceived behavioral control and ultimately reducing the use of hookah.

Keywords: attitude, women, perceived behavioral control, education Paper Type: Research Article.

Citation (Vancouver): Hasani L, Aghamolaei T, Ezati rad R, Ahmadzadeh Kh, Ghanbar nejad A. Attitude and Perceived Behavioral Control Toward Reducing water pipe Use in Women. Iran J Health Educ Health Promot. Winter 2021;8(4): 299-308. [Persian]x

Citation (APA): Hasani L., Aghamolaei T., Ezati rad R., Ahmadzadeh Kh., Ghanbar nejad A. Attitude and Perceived Behavioral Control Toward Reducing water pipe Use in Women. Iranian Journal of Health Education \& Health Promotion., 8(4), 299-308 . [Persian] 


\section{بررسى نكرش و كنترل رفتارى درك شده نسبت به كاهش استعمال قليان در زنان}

\section{جكيده}

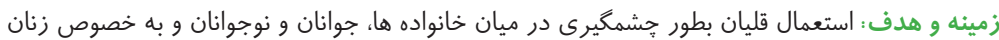

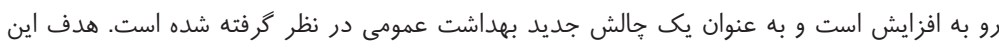

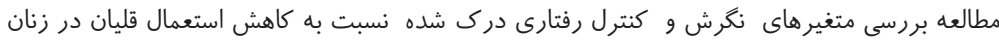

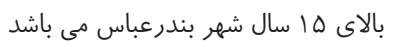

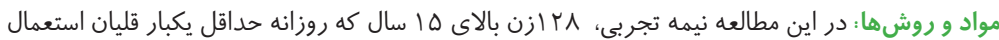

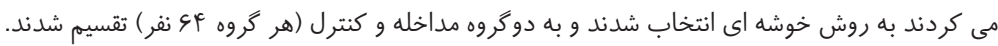

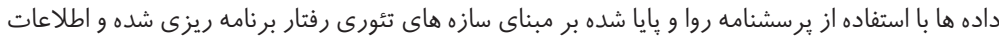

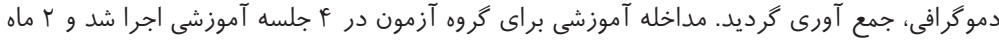

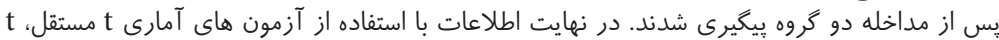

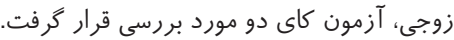

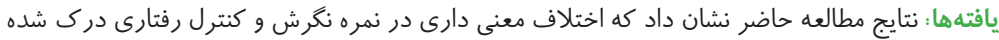

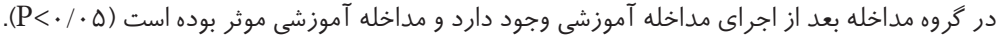

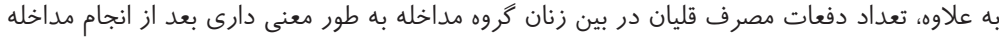

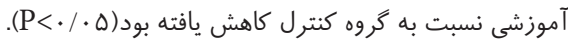

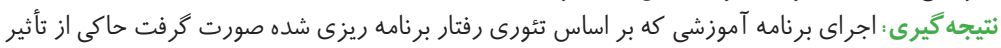

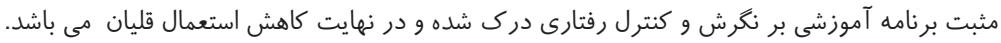

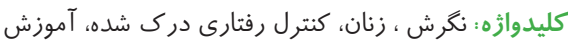

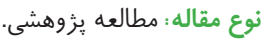

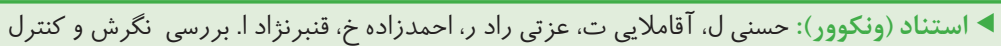

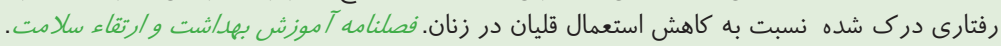

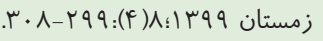

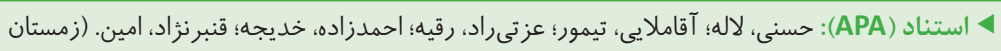

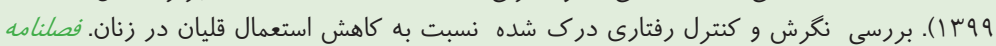

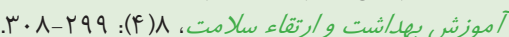

دانشيارآموزش بهداشت ، مركز تحقيقات مراقبتهاى

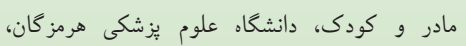
بندرعباس، ايران تيمور آقاملايى آنيى استاد آموزش بهداشت، مر كز تحقيقات عوامل اجتماعى آنقي

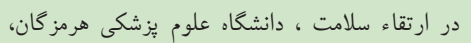
بندرعباس، ايران رقيه عزتى راد ، مدانشجوى دكترى آموزش بهداشت و وارتقا سلامت

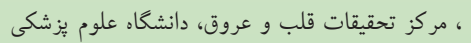

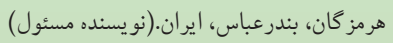
Ezati_rad@yahoo.com

خد يجه احمدزاده

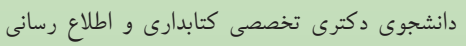

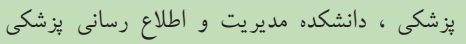
دانشكاء علوم بزشكى اصفهان، اصفهان ، ايران امين قنبر نزّاد دانشجوى دكترى تخصصى آمار زيستى، مركز

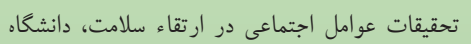
علوم يزشكى هرمز كان، بندرعباس، ايران. تاريخ د ريافت: 1 | | |

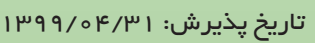




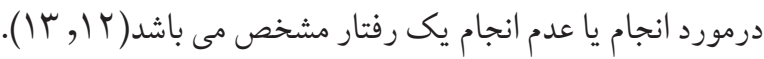
دومين عاملى كه روى قصد افراد براى انجام رفتار و يا عدم انجام

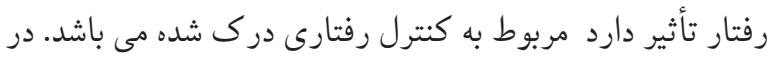
تئورى رفتار برنامه ريزى شده كنترل رفتارى درك شده به عنوان

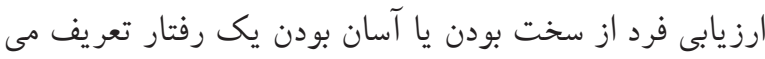

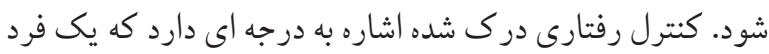
احساس مى كند انجام دادن يا ندادن يكى رفتار تحت كنترل ارادى دئ داري

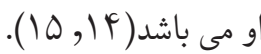
بيشتر مطالعات انجام شده در كشور، فقط شيوع استعمال قليان

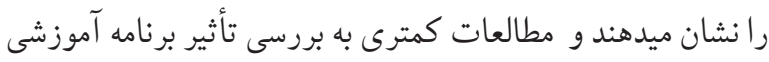

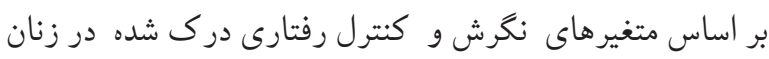

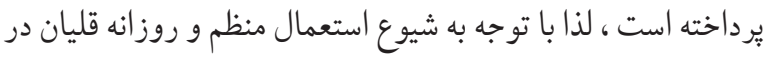

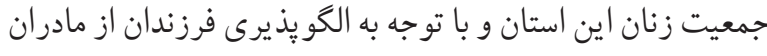

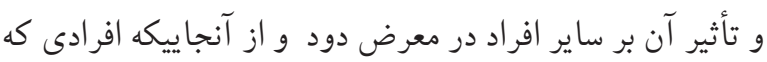

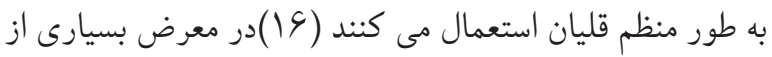

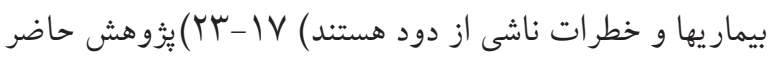

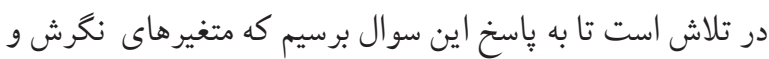

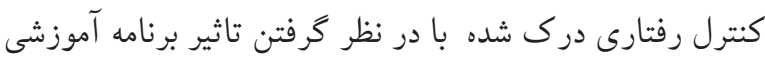
در كاهش استعمال قليان جه تاثيرى دارند؟ دأن

مو اد و روش ها يُّوهش حاضر يك مطالعه مداخله اي از نوع نيمه تجربى مى باشد.

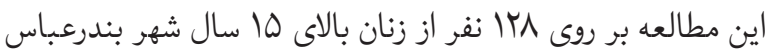

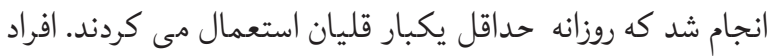
در دو كروه مداخله و كنترل قرار كرفتند. محيط يُّوهشى اين تحقيق F ناحيه از شهر بندرعباس (مركز بهداشتى درمانى شهرستان

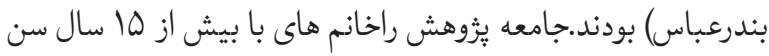

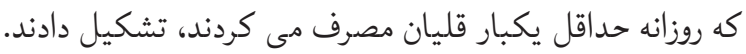

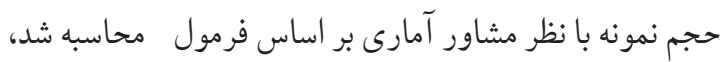

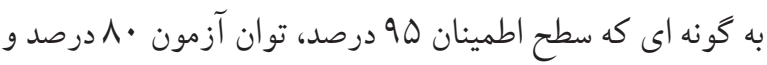

قليان يك روش قديمى استعمال دخانيات است كه جهت استفاده از توتون به كار مى رود و در مناطق مختلف داراى نام هاى كوناكون مى باشد( (). قليان داراى غلظت بالاى مونوكسيد كربن، نيكوتين

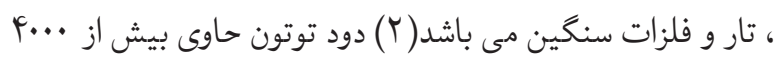

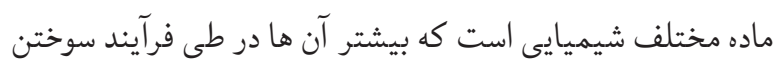

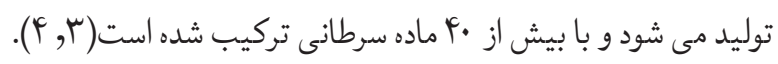

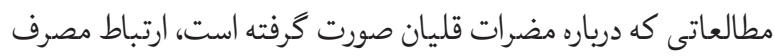

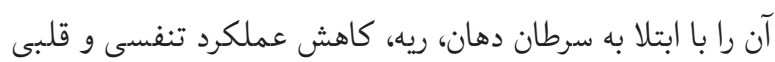

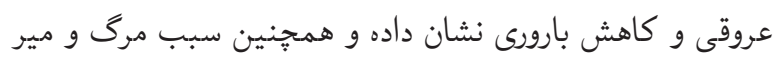
زودرس و سنكوب مى شود (ه) . در بسيارى از مناطق شيوع استعمال

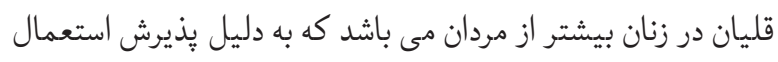

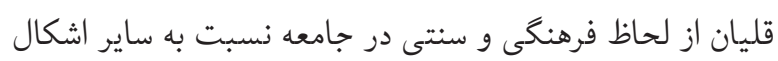
دخانيات است(Y, V) .در ميان زنان عرب و و بسيارى از كشورهاى ديخر مصرف قليان قبح و شرم كمترى نسبت به مصرف سيكار

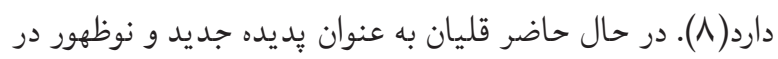

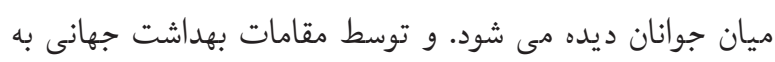
عنوان إيبدمى جهانى دخانيات ناميده شده است (9, • (1).

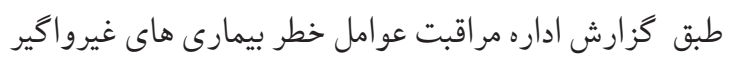
وزارت بهداشت در سال الو إو و مقايسه عوامل خطر مهم بيمارى هاى غيرواكير در استان هرمز كان با ساير استان ها بر اساس دادها

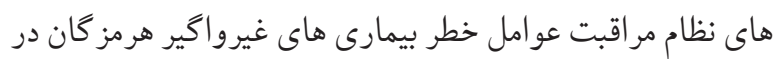
رتبه بنجم كشورى از نظر ميزان درصد افرادى كه روزانه قليان

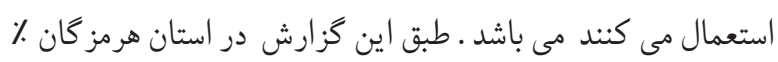

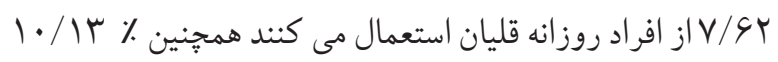
از زنان و \% 19/ه از مردان در اين استان روزانه قليان استعمال

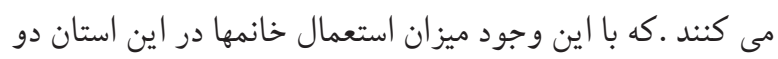

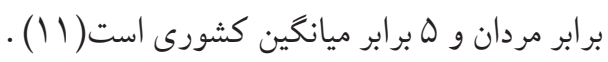
اولين عاملى كه روى قصد افراد براى انجام رفتار و يا عدم

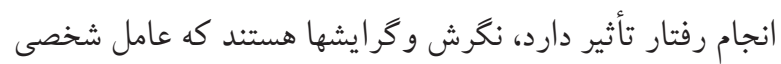

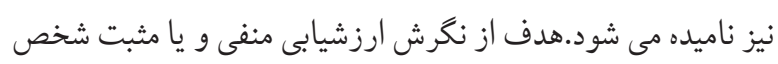


مواد دخانى ،استعمال قليان در گروه هاى سنى مختلف ، تاريخجه

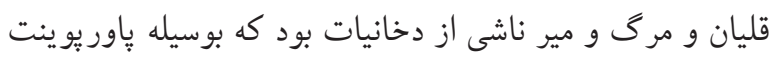

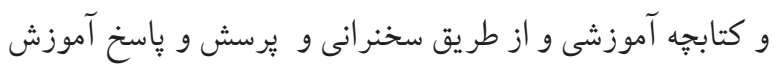

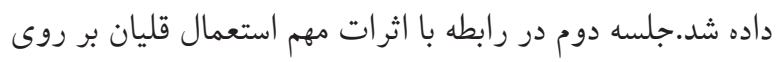

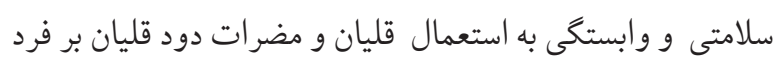

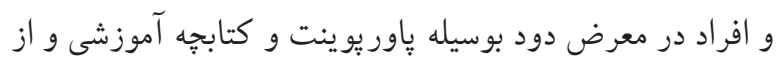
طريق سخنرانى و يرسش و ياسخ آموزش داده شد و همدينين

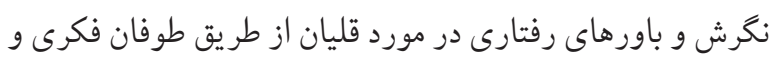

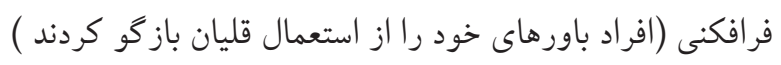

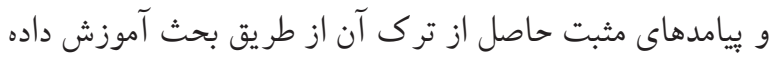
شد. جلسه سوم آموزشى در مورد باورهاى كنترل شده و عوامل

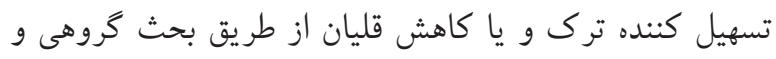

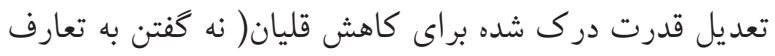
اطر افيان براى كشيدن قليان، مقابله با وسوسه هاى كشيدن قليان، توانايى(راهكارهاى) صرف نظر از كشيدن قليان در هنكام تفريح و شادى، توانايى (راهكارهاى) صرف نظر كردن از كشيدن قليان

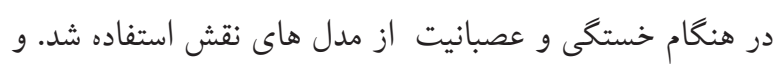
همجنين برنامه ريزى براى ترك از طريق بحث و يرسش و و پِاسخ آموزش داده شد.

بعد از دو ماه از اجراى برنامه مداخله، بِ ديس آزمون انجام شد و

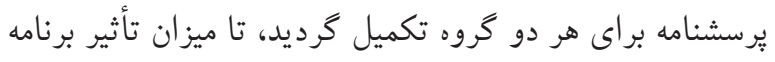

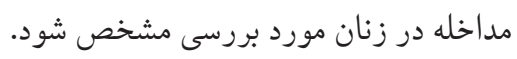

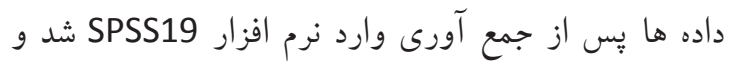
بوسيله آزمون هاى آمارى t مستقل جهت مقايسه مقادير كمى بين وادي

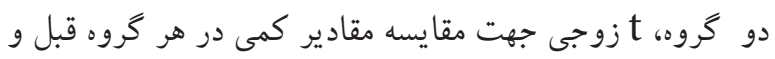

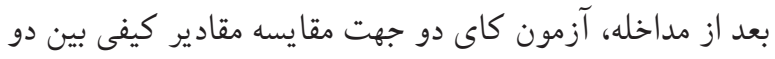

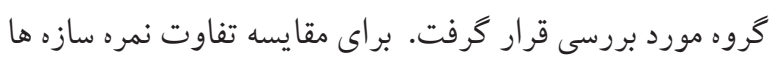

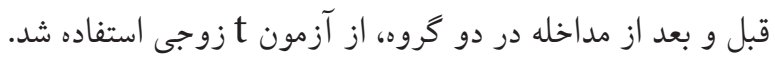

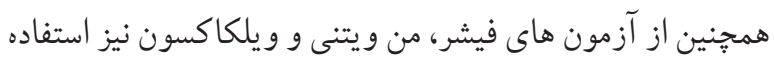

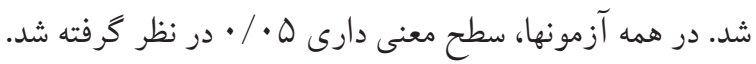

اختلاف استاندارد شده ه / • در نظر گرفته شد.روش نمونه گيرى براى انتخاب نمونه ها از نوع خوشه اى تصادفى بود. بدين صورت

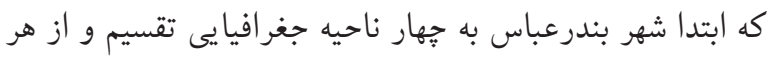

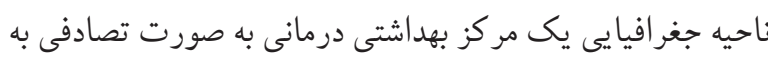

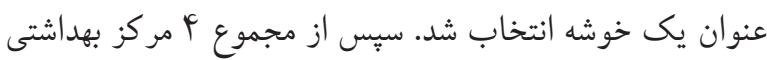
درمانى انتخاب شده به طور تصادفى دو مر كز بهداشتى به كزينش

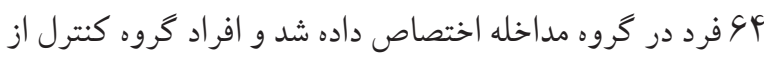

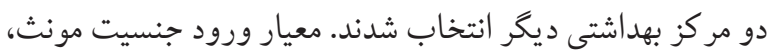

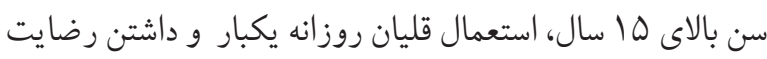

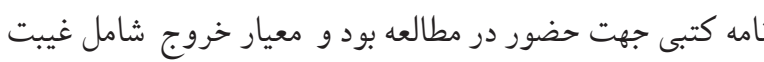
بيش از يك جلسه و غير قابل دسترس بودن فرد بعلت تغيير محل زندگى وى بودند. در اين بررسى، داده ها از طريق يُرسشنامه از طريق مصاحبه

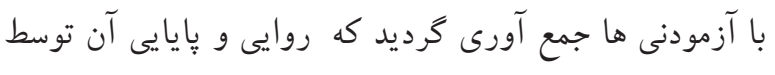

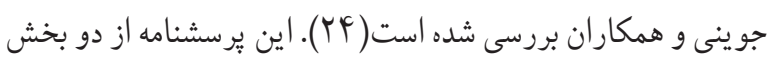
تشكيل شده بود: سوالات بخش اول شامل سن، جنس، وضعيت

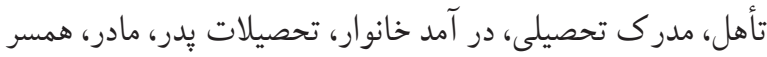

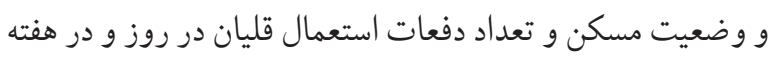
و سابقه استعمال قليان مى باشد. بخش دوم مربوط به سو الات سازه

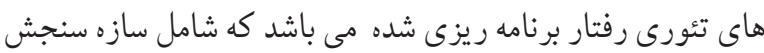

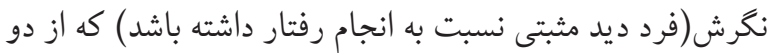
زير سازه اعتقادات رفتارى و ارزشيابى يِيامد تشكيل شده است و و سازه كنترل رفتارى درى شده (فرد احساس كند قادراست رفتار

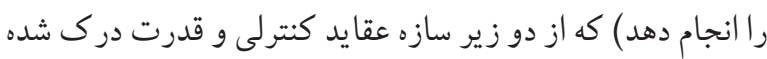
تشكيل شده است . برنامه آموزشى بر اساس اطلاعات بيش دآ آزمون

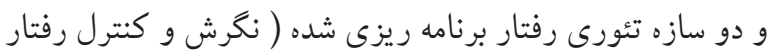

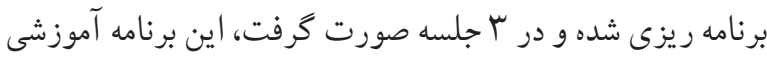

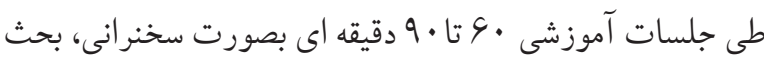
كروهى، يرسش و پِاسخ، ايفاى نقش و در اختيار دادن كتابجه

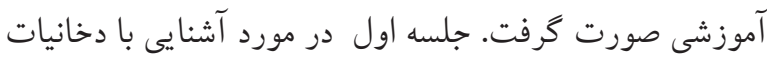
و اثرات آن بود كه در زمينه إييدميولوزى مصرف درونه 
جدول ا. اطلاعات دموگرافيك و ميانگين اختلاف نمرات قبل و بعد از مداخله در دو گروه كنترل و مداخله

ميانغين اختلاف نمرات قبل و بعد از مداخله

\begin{tabular}{|c|c|c|c|c|c|c|c|c|}
\hline \multicolumn{2}{|c|}{ كنترل رفتارى درى شده } & \multicolumn{2}{|c|}{ 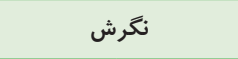 } & \multirow[t]{2}{*}{ درصد } & \multirow[t]{2}{*}{ تعداد } & \multirow[t]{2}{*}{ 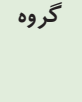 } & \multicolumn{2}{|c|}{ متغير هاى زمينه اى مهم } \\
\hline SD & Mean & SD & Mean & & & & & \\
\hline$r \mid / 1 \Lambda$ & $1 . / 1 r$ & IV/Or & $\Lambda / \mu r$ & $\% .4 \cdot / \Delta \Delta$ & 10 & كنترل & \multirow{2}{*}{ كمتر يا مساوى SD } & \multirow{10}{*}{ سال) } \\
\hline TN/IN & $r r / r r$ & YN/GA & r. & $\% F q / F$. & ir & مداخله & & \\
\hline $1 r / 1 r$ & $9 / F$ & $1 \mu / v V$ & $9 / 9 V$ & $\% F F / 1$. & 10 & كنترل & \multirow{2}{*}{ rF } & \\
\hline$r N / \cdot r$ & $r V / V F$ & $r T / \Delta F$ & rN/Vq & $\% \Delta \Delta / q$ & 19 & مداخله & & \\
\hline$r \mu / r \Delta$ & 11 & $1 \% / 94$ & s/Vq & $\% \Delta \mu / \Lambda$. & If & كنترل & \multirow{2}{*}{ FF } & \\
\hline$r q / 99$ & ro & $r F / G F$ & $r V / F r$ & $\% \uparrow s / r$. & Ir & مداخله & & \\
\hline $11 / 11$ & $\Delta$ & $\mid r / \cdot r$ & $\mathrm{~V} / \mathrm{\mu}^{\mathrm{N}} \mathrm{A}$ & $\% \Delta \cdot /$. & 19 & كنترل & \multirow{2}{*}{ G. ti \& } & \\
\hline$r V / \Delta \Lambda$ & $F G / F F$ & $19 / 9 \mathrm{~V}$ & 49 & $\% 0 \cdot / \cdot$ & 19 & مداخله & & \\
\hline$r r / 11$ & rr & rN/GF & $\Delta / V \Delta$ & $\% F F / f$. & r & كنترل & \multirow{2}{*}{ بيشتر از · c } & \\
\hline $19 / V Y$ & $r \cdot / r$ & $19 / \mu r$ & rs & $\% \Delta \Delta / \varsigma$. & $\Delta$ & مداخله & & \\
\hline $11 / 19$ & $11 / 90$ & $|N / 1|$ & $1 \cdot / r \Delta$ & $\% \Delta \Delta / \varsigma$. & $r$. & كنترل & \multirow{2}{*}{ 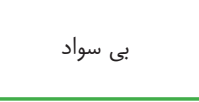 } & \multirow{10}{*}{ تحصيلات } \\
\hline 19,99 & $\Gamma \wedge, \mathcal{\prime}$ & $r \cdot, 19$ & $r Y / G T$ & $\% F q / F$. & 18 & مداخله & & \\
\hline $\mid F / r \Lambda$ & $N / \Delta S$ & $1 \pi / 9$ & $\Lambda / 1 \Lambda$ & $\% \triangleright \Delta / q$ & IV & 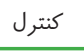 & \multirow{2}{*}{ ابتدايى } & \\
\hline rr/fs & $r \Delta / \uparrow \Delta$ & $r \cdot / r \wedge$ & $p \cdot / \cdot \Delta$ & $\% \Delta F / 1$. & $r$. & مداخله & & \\
\hline$r \cdot / r q$ & $G / T^{F}$ & Ir & $r / \Delta q$ & $\% \Delta \cdot /$. & IV & كنترل & \multirow{2}{*}{ سيكل } & \\
\hline rV/rr & $r q / 1 r$ & $\Gamma 1 / \Delta q$ & $r N / I r$ & $\% \Delta \cdot / \ldots$ & IV & مداخله & & \\
\hline$r r / r q$ & $1 r / r$ & $19 / F$ & $1 \cdot / 1$ & $\%, \Delta$ & 1. & كنترل & \multirow{2}{*}{ دييلم } & \\
\hline$r \Delta / s \Lambda$ & rr & $\mu F / s V$ & $r \cdot / \kappa$ & $\% \cdots, \Delta$ & 1. & مداخله & & \\
\hline$\cdot$ & . & & . & $\%$ & $\cdot$ & كنترل & \multirow{2}{*}{ فوق دييلم } & \\
\hline . & V & & ro & $\% \ldots$ & 1 & مداخله & & \\
\hline $10 / T S$ & N/IV & $19 / 94$ & l./Ar & \% & 4 & كنترل & \multirow{2}{*}{ كمتر از ؟ نفر } & \multirow{10}{*}{ بعد خانوار } \\
\hline$r \mathrm{~N} / \mathrm{r}$ & $r s / r r$ & rN/IT & $F r / \Delta$ & ※s૬/V. & Ir & مداخله & & \\
\hline$r \cdot / \Delta \Delta$ & $1 r / 11$ & $10 / \mu$ & $11 / 11$ & \%s & 9 & كنترل & \multirow{2}{*}{ r } & \\
\hline$r V / F q$ & $r r / q F$ & $r \cdot / \mu \wedge$ & $r \Delta / \Delta \varphi$ & 1.94 & 19 & مداخله & & \\
\hline$r r / q r$ & $q / r V$ & $\mid N / F$ & $r / 9 F$ & $\% \Delta \Delta$ & 11 & كنترل & \multirow{2}{*}{$r$} & \\
\hline$r F / \Delta r$ & $r q / \Delta \varphi$ & $r \Delta / I V$ & $\mu F / F F$ & $\% \Delta$ & 9 & مداخله & & \\
\hline $\mid N / F \wedge$ & $\wedge$ & $1 r / 94$ & V & $\% \Delta 9$ & $r \mu$ & كنترل & \multirow{2}{*}{$\Delta$} & \\
\hline$r q / r \Delta$ & $r \cdot / \mu l$ & $r F / 9 \Lambda$ & $\forall S / \Delta G$ & $\% \notin 1$ & 19 & مداخله & & \\
\hline $\mid V / r q$ & $1 \cdot / 9$ & $10 / .9$ & $1 \cdot / \cdot V$ & $\% \Delta \mathrm{V} / \mathrm{V}$ & 10 & كنترل & \multirow{2}{*}{ بيشتر از م نفر } & \\
\hline$r F / v q$ & $r q / 91$ & $r 1 / F$ & Ff & $\% \uparrow r / r$. & 11 & مداخله & & \\
\hline $\mid r / \Delta F$ & $\Delta / G F$ & $1 r / 90$ & $\Delta / \uparrow \Delta$ & $\% \leftarrow r / r$. & 11 & كنترل & \multirow{2}{*}{ 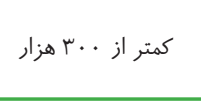 } & \\
\hline$r$ r & $r \cdot / q v$ & $r \mu / r v$ & rN/qr & $\% \Delta V / V$ & 10 & مداخله & & \\
\hline$r \mid / . \Delta$ & $11 / \wedge \Lambda$ & $19 / 4 \Delta$ & $q / \cdot r$ & $1.9 \cdot / r$. & $F q$ & كنترل & 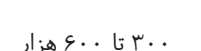 & \\
\hline$T F / T V$ & rI/or & $r F / r V$ & $F 1 / q \mu$ & $\%$ \%/v. & $r q$ & مداخله & मी & در آهد ماهيانه خانوار \\
\hline$V / T V$ & $r / f F$ & $11 / 1$ & $\Delta / F F$ & $\% 4 \cdot / 9$. & 9 & كنترل & V. ت تا كي مطلون & (تومان) \\
\hline $\mathrm{rV} / \mathrm{\Lambda \Lambda}$ & $r \Delta / \mu \wedge$ & $r \Delta / \Delta \Lambda$ & $r \cdot / 9 r$ & $\% \Delta 9 / 1$ & 14 & مداخله & 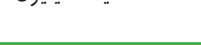 & \\
\hline . & . & 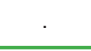 & . & $\%$ & $\cdot$ & كنتر ل & بشت لز لمبلدن & \\
\hline rV/AT & $r r / \Delta V$ & $r F / G r$ & $F r / \Delta V$ & $\% \ldots$ & $\checkmark$ & مداخله & יب & \\
\hline
\end{tabular}




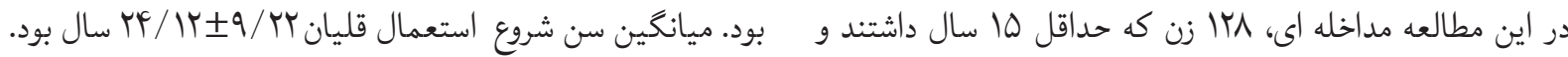

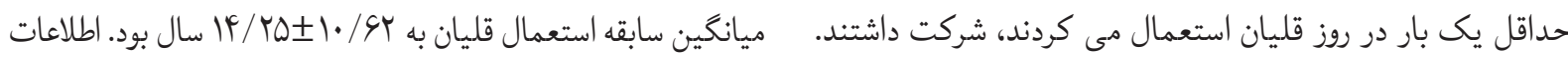
نيمى از اين زنان در كروه مداخله و نيمه ديخر متعلق به كروه بيشتر در جدول الرائه شده است. كنترل بودند. در هر دو كروه حدود نيمى از شركت كنندگان داده هاى جدول شماره ب نشان داد در سازه نخرش (نمره كل) متاهل بودند. سطح تحصيلات رنان شركت كننده در مطالعه از و زير سازه هاى آن و همجنين در سازه كنترل رفتارى درك شده بى سواد تا مدرك دييلم متغير بود در هر دو كروه شغل اكثريت و زير سازه هاى آن قبل از مداخله تفاوت معنادارى بين دو كروه

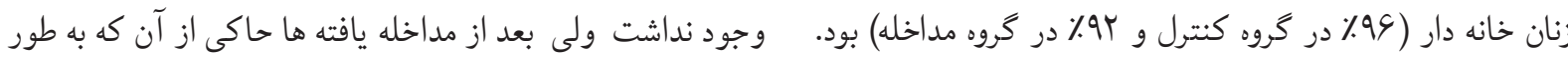

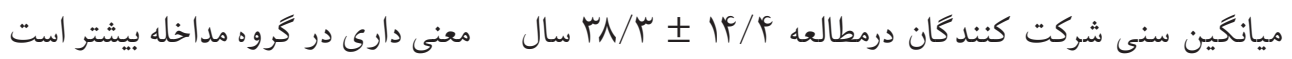
جدول r. مقايسه ميانگين نگرش و كنترل رفتار درى شده در گروه كنترل و مداخله قبل و بعد از مداخله

\begin{tabular}{|c|c|c|c|c|c|c|c|}
\hline \multirow{2}{*}{ P-value } & \multirow{2}{*}{ آماره آزمون } & \multicolumn{2}{|c|}{ مداخله } & \multicolumn{2}{|c|}{ كنترل } & \multirow{2}{*}{ زمان } & \multirow{2}{*}{ 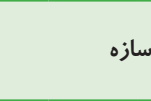 } \\
\hline & & انحراف معيار & ميانكين & انحراف معيار & ميانغين & & \\
\hline.$/ I V Y$ & $-1 /$ rsG $^{b}$ & $19 / 9 \pi$ & $10 / 9 V$ & $r \cdot / 19$ & $9 / 99$ & قبل از مداخله & \multirow{4}{*}{ نكرش } \\
\hline$<\cdot /\left.\cdot\right|^{*}$ & $-\Lambda / r \subseteq G^{a}$ & $r N / \Delta V$ & $\Delta \mathrm{V} / \cdot \mathrm{G}$ & $r \Delta / r \varphi$ & $1 V / 09$ & بعد از مداخله & \\
\hline$<\cdot /\left.\cdot \cdot\right|^{*}$ & $-9 / 199 G^{a}$ & $r s / 10$ & $91 / .9$ & $10 / 11$ & $V / 91$ & اختلاف قبل و بعد از مداخله & \\
\hline--- & ---- & \multicolumn{2}{|c|}{$<\cdot /\left.\cdot\right|^{\text {* }}$} & \multicolumn{2}{|c|}{$<\cdot /\left.\cdots\right|^{*}$} & P-value & \\
\hline
\end{tabular}

\begin{tabular}{|c|c|c|c|c|c|c|c|c|}
\hline 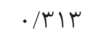 & $-1 / \cdot 1 \cdot b$ & $s / \cdot r$ & $r$ r/Ar & $\Delta / \wedge 1$ & $r I / F \Delta$ & قبل از مداخله & \multirow{4}{*}{ باورهاى } & \multirow{8}{*}{ 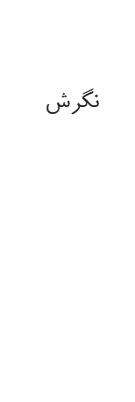 } \\
\hline$<\cdot /\left.\cdot\right|^{*}$ & $-\Delta / \varsigma \mu \mu^{b}$ & $\Delta / 1 \Lambda$ & $r \wedge / \wedge \Lambda$ & $\Delta / \& V$ & $r Y / V Y$ & بعد از مداخله & & \\
\hline$<\cdot /\left.\cdot\right|^{* *}$ & $-s / 19 A^{b}$ & $r / V s$ & $9 / \cdot 0$ & $r / v q$ & $1 / r V$ & اختلاف قبل و بعد از مداخله & & \\
\hline \multicolumn{2}{|c|}{---------- } & \multicolumn{2}{|c|}{$<\cdot /\left.\cdot \cdot\right|^{*}$} & \multicolumn{2}{|c|}{$\cdot / \cdot r *$} & P-value & & \\
\hline$\cdot / r G F$ & $-\cdot / 9 \cdot 1^{b}$ & $r / \cdot \Lambda$ & $r / \cdot r$ & $r / \cdot r$ & $r / I r$ & قبل از مداخله & & \\
\hline$<\cdot /\left.\cdot\right|^{*}$ & $-s / f \Delta \Lambda^{b}$ & $r / f F$ & $9 / \mu^{-9}$ & $F / V F$ & $\mu / \Delta \Delta$ & بعد از مداخله & ارزشيابى & \\
\hline$<\cdot /\left.\cdot\right|^{*}$ & $-s / V \cdot \mu^{b}$ & r/A & $s / \mu F$ & $r / V \Delta$ & $1 / 4 r$ & اختلاف قبل و بعد از مداخله & بيامد & \\
\hline \multicolumn{2}{|c|}{---------- } & \multicolumn{2}{|c|}{$<\cdot /\left.\cdot \cdot\right|^{*}$} & \multicolumn{2}{|c|}{$<\cdot /\left.\cdots\right|^{* *}$} & P-value & & \\
\hline$\cdot / r q 1$ & $-1 / \cdot F \cdot b$ & $F r / f F$ & $r / r s$ & rI/AV & $1 \cdot / \gamma_{-}$ & قبل از مداخله & & \multirow{11}{*}{ كنترل رفتارى شده } \\
\hline$<\cdot /\left.\cdot \cdot\right|^{*}$ & $\Delta / F F \cdot b$ & $F r / \Delta \Delta$ & $r F / \Delta r$ & $r N / \cdot V$ & $-\cdot / \mathrm{V} \wedge$ & بعد از مداخله & مجموع كنترل & \\
\hline$<\cdot /\left.\cdot \cdot\right|^{*}$ & $-\Delta / \Delta \cdot c^{b}$ & $\mathrm{rV} / .9$ & $r r / I V$ & $1 N / \Delta S$ & $9 / 09$ & اختلاف قبل و بعد از مداخله & رفتارى درى شده & \\
\hline \multicolumn{2}{|c|}{---------} & \multicolumn{2}{|c|}{$<\cdot /\left.\cdot \cdot\right|^{*}$} & \multicolumn{2}{|c|}{$<\cdot /\left.\cdot\right|^{*}$} & P-value & & \\
\hline$\cdot /\left.\cdot r\right|^{*}$ & $-r / T_{1} S^{b}$ & $9 / 49$ & $|N / 9|$ & $\Lambda / F r$ & $10 / 9 V$ & قبل از مداخله & \multirow{4}{*}{ كنترل } & \\
\hline$<\cdot /\left.\cdot\right|^{\text {* }}$ & $-\Delta / \Delta r s^{b}$ & $V / r V$ & $r \Delta / \wedge q$ & $N / F F$ & $\mid V / \widetilde{\mu}$ & بعد از مداخله & & \\
\hline$<\cdot /\left.\cdot\right|^{*}$ & $-\Delta / \Delta 9 Y^{b}$ & $4 / .1$ & $9 / 91$ & $r / \Lambda \Lambda$ & $1 / v$ & اختلاف قبل و بعد از مداخله & & \\
\hline \multicolumn{2}{|c|}{-------- } & \multicolumn{2}{|c|}{$<\cdot /\left.\cdot \cdot\right|^{\text {*** }}$} & \multicolumn{2}{|c|}{$<\cdot /\left.\cdot \cdot\right|^{*}$} & P-value & & \\
\hline.$/ .99$ & $-1 / 9 V V^{b}$ & $9 / \cdot{ }^{4}$ & $-r / 14$ & s/IV & $-f / q$. & قبل از مداخله & \multirow{3}{*}{ درى شدرت } & \\
\hline$<\cdot /\left.\cdot\right|^{*}$ & $-\Delta / r Y S^{b}$ & $V / r q$ & $\Delta / \mu \wedge$ & V/Dr & $-r / F 1$ & بعد از مداخله & & \\
\hline \multirow[t]{2}{*}{$<\cdot /\left.\cdot\right|^{*}$} & $-F / 9 G F b$ & $s / r \mu$ & $V / \Delta r$ & $F / F q$ & $r / \uparrow q$ & اختلاف قبل و بعد از مداخله & & \\
\hline & & & ----- & & $<\cdot /$ & $<\cdot$ & P-va & ue \\
\hline
\end{tabular}


جدول س. مقايسه ميانگين دفعات استعمال قليان قبل و بعد از مداخله در گروه مداخله و كنترل

\begin{tabular}{|c|c|c|c|c|c|c|c|c|}
\hline \multirow[b]{2}{*}{ P-Value } & \multirow{2}{*}{ آماره آزمون } & \multirow{2}{*}{ ميانكين ها " اختلاف } & \multicolumn{2}{|c|}{ بعد از مداخله } & \multicolumn{2}{|c|}{ قبل از مداخله } & \multirow{2}{*}{\multicolumn{2}{|c|}{ سازه }} \\
\hline & & & انحراف & ميانغين & انحراف & ميانكين & & \\
\hline.$/ 418$ & $-\cdot / \Delta \cdot$ & $-\cdot / \cdot r$ & $1 / 01$ & $\Gamma / \mu \Delta$ & $1 / \Delta \Lambda$ & r/r人 & دفعات استعمال قليان & \multirow{2}{*}{ گروه كنترل } \\
\hline$\cdot / 4 \cdot q$ & $-\cdot /$ Ard & $-\cdot /$ / & $1 \cdot / 4 r$ & $18 / T V$ & $11 / 1 F$ & س & دفعات استعمال قليان & \\
\hline$<\cdot /\left.\cdot\right|^{*}$ & $-Q / F T F$ & $-1 / 99$ & I/rs & $1 / 4$ & $r / \mu r$ & $r / \Delta S$ & دفعات استعمال قليان & \multirow{2}{*}{ كروه مداخله } \\
\hline$<\cdot /\left.\cdot \cdot\right|^{*}$ & $-s / r q f$ & $-1 \% / 0$ & $1 / 99$ & $9 / 49$ & $10 / \Delta r$ & $r \mu / 1 s$ & دفعات استعمال قليان & \\
\hline
\end{tabular}

a - اختلاف بعد از مداخله نسبت به قبل از مداخله سنجيده شده است. ق* تفاوت معنادار در سطح ه • • و وجود دارد.

طبق يافته هاى جدول شماره ب بر اساس نتايج آزمون t زوجى تئورى بركاهش استعمال قليان انجام شد گزارش كردند كه بين

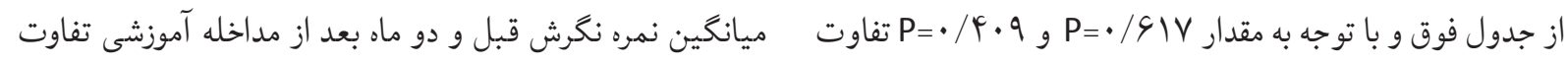

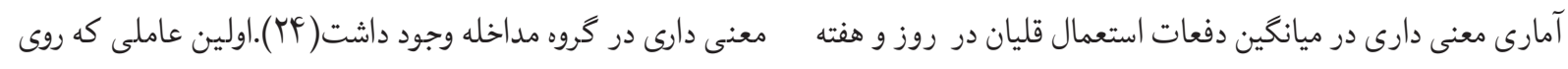

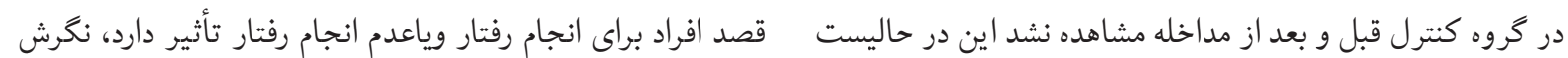

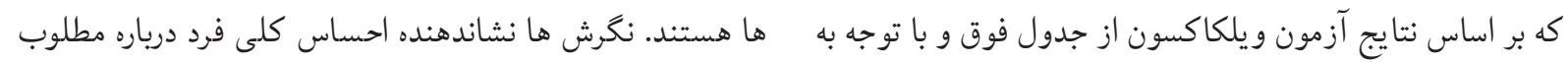

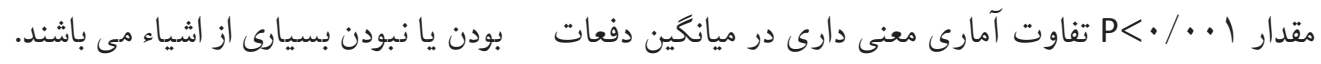

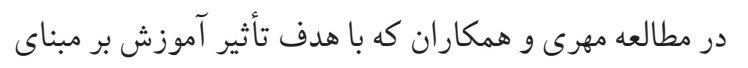

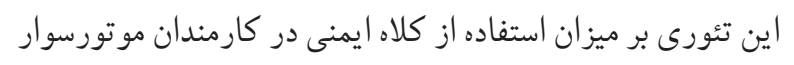
صورت كرفت نشان داد كه بعد از مداخله آموزشى ميانخين نمره نكرش در كروه كنترل در خصوص استفاده از كلاه ايمنى افزايش

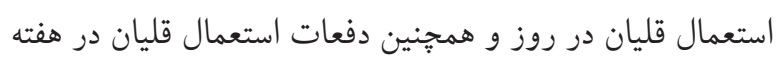
در گروه مداخله، قبل و بعد از مداخله مشاهده شد. طبق يافته هاى دوني

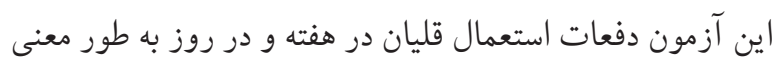
دارى بعد از مداخله كاهش يافته بود. يافت(Y) (T) نتايج مطالعه احمدى طباطبايى وهمكاران در زمينه

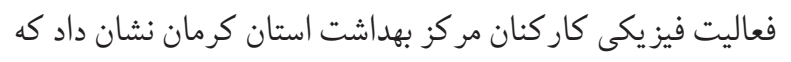
بحث در ميانكين تفاضل نمرات سازه هاى تئورى قبل و بعد از مداخله اختلاف معنى دارى بين گروه مداخله و كنترل مشاهده نشد. نتايج

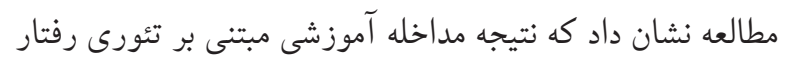

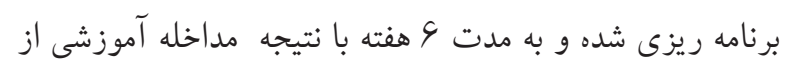

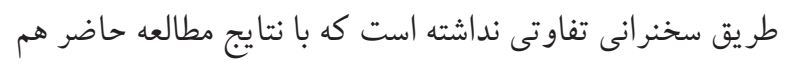
خوانى ندارد(YV)؛ شايد بتوان به نقش موثرى كه استفاده صحيح

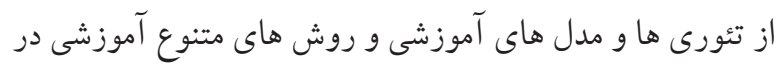

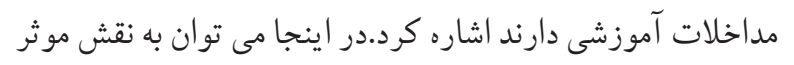

با توجه به نتايج مطالعه حاضر بركزارى جلسات آموزشى در خصوص سازه نكرش مثبت بوده و اختلاف معنى دار در تفاضل ميانكين نمره

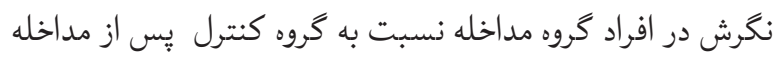

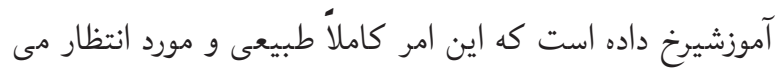

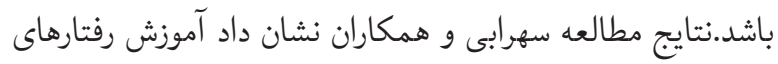
سالم در نگرش دانشجويان نسبت به سوء مصرف مواد مى تواند

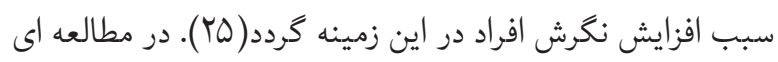
كه توسط جوينى و همكاران با هدف تأثير آموزش بر مبناى اين كردين 
شايد بتوان به نقش رسانه هاى گروهى ارتباط داد وشايد بتوان جنين

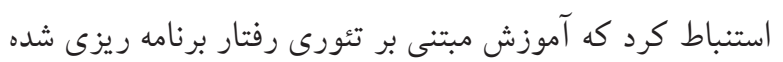

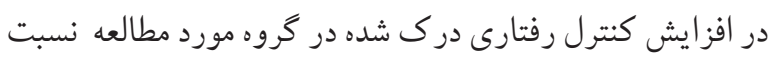

$$
\text { نبه ساير روش هاى آموزشى تأثير بيشترى را دارد. }
$$

با توجه به اهميت و تأثير برنامه آموزشى مبتنى بر كنترل رفتارى

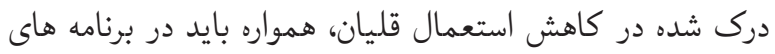

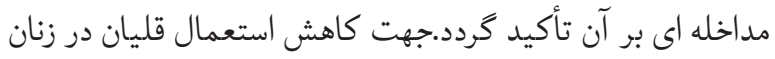
بكاركيرى استراتثى و برنامه آموشى كه در اين مطالعه طراحى و و نو بكار كرفته شده است به عنوان يك الخو توصيه و مورد تأكيد قرار مى گيرد. از محدوديت هاى اين مطالعه مى توان به عدم اعتماد بسيارى از خانمها به كروه تحقيق نام برد و از آنجاييكه استعمال

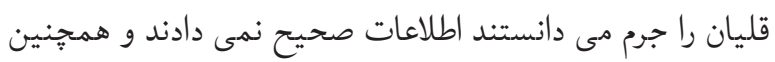

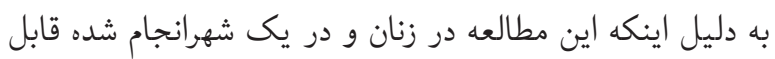
تعميم و مقايسه با مردان و ساير شهرها نيست. با توجه به موثر بودن آموزش بر كاهش استعمال قليان بيشنهاد

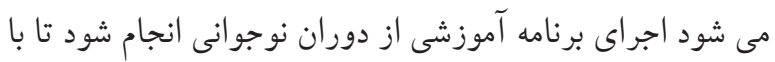

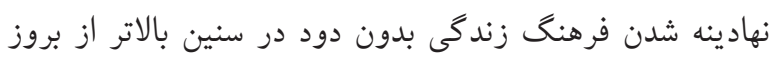
سوارض جدز ارى استعمال دخانيات جلو گيرى شود. نويسند گان مقاله از معاونت تحقيقات و فناورى دانشگاء علوم يزشكى هرمزگان جهت تصويب و حمايت مالى اين طرح با كد

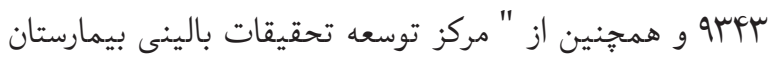
شهيد محمدى" تشكر و قدردانى مى نمايند.

\section{References}

1. Dehdari T, Jafari A, Joveyni H. Students' perspectives in Tehran University of Medical Sciences about factors affecting smoking hookah. Razi Journal of Medical Sciences. 2012;19(95):17-24.

2. Makvandi Z, Sharifi M, Barati M. Assessment of Factors Associated With Hookah Consumption Among College Students of Asad Abad City Base on The Theory of Planned Behavior (TPB) in 2015-2016. Iranian Journal of Health Education and Health Promotion. 2017;5(4):270-9.
روشهاى آموزشى همجيون طوفان فكرى در تقو يت نكرش مثبت

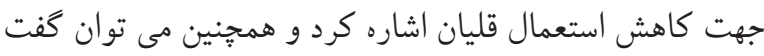
بحث روش آموزشى مناسب جهت افزايش نكرش در كاهش استعمال

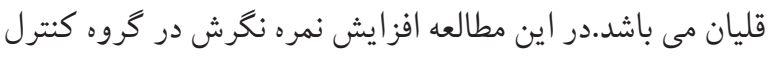

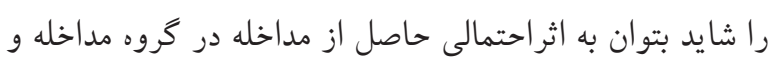
ارتباط غيرمستقيم با افراد گروه مداخله مرتبط دانست.

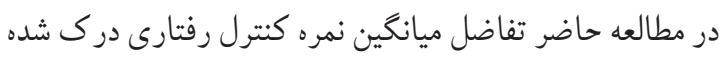

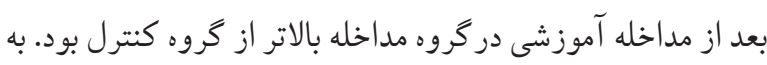

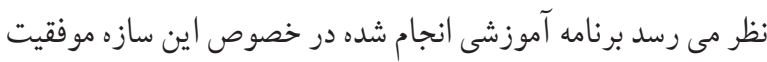

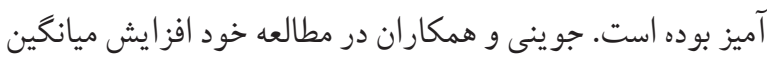
نمره كنترل رفتارى درك شده بعد از مداخله آموزشى در كروه مداخله

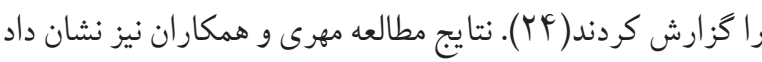
استفاده از تئورى رفتار برنامه ريزى شده در امر آموزش مى تواند كنترل رفتارى درى شده كارمندان موتورسوار در مورد استفاده از

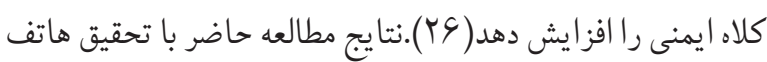
نيا و همكاران درمورد افزايش كنترل رفتارى درك شده در انجام

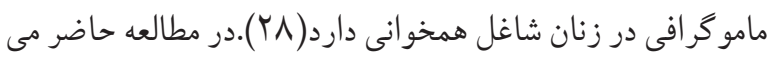

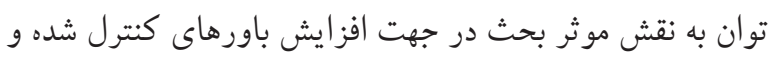

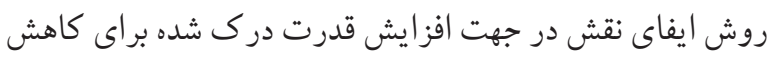

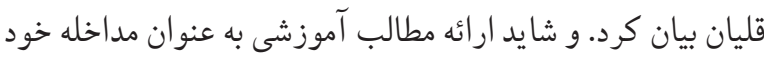

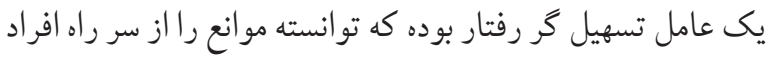
مورد مطالعه بردارد و شايد با ارائه مشوق هايى از قبيل نداشتن

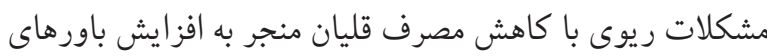
كنترل و در نهايت افزايش كنترل رفتارى درك شده شود.در اين بائ مطالعه افزايش نمره كنترل رفتارى درك شده در كروه كنترل را

https://doi.org/10.30699/acadpub.ijhehp.5.4.270

3. Kuper H, Adami HO, Boffetta P. Tobacco use, cancer causation and public health impact. Journal of internal medicine. 2002;251(6):455-66. https://doi.org/10.1046/j.1365-2796.2002.00993.x PMid:12028500

4. Feliu A, Fu M, Russo M, Martinez C, Sureda X, Lopez MJ, et al. Exposure to second-hand tobacco smoke in waterpipe cafes in Barcelona, Spain: An assessment of airborne nicotine 
and PM2.5. Environmental research. 2020;184:109347. https://doi.org/10.1016/j.envres.2020.109347 PMid:32179267

5. Shaikh R, Vijayaraghavan N, Sulaiman A, Kazi S, Shafi M. The acute effects of waterpipe smoking on the cardiovascular and respiratory systems. J Prev Med Hyg. 2008;49(3):1017.

2. Panahi R, Ramezankhani A, Tavousi M, HaeriMehrizi A, Niknami S. Reinforcing the performance of health belief model using health literacy in anticipating adoption of smoking preventive behaviors in university students. Journal of Health Literacy. 2018;3(1):39-49. https://doi.org/10.22038/jhl.2018.10930

7. Heydari G, Taghizdeh F, Fazlzadeh M, Jafari AJ, Asadgol Z, Mehrizi EA, et al. Levels and health risk assessments of particulate matters (PM 2.5 and PM 10) in indoor/outdoor air of waterpipe cafés in Tehran, Iran. Environmental Science and Pollution Research. 2019;26(7):7205-15. https://doi.org/10.1007/s11356-019-04202-5 PMid:30656582

8. Koul PA, Hajni MR, Sheikh MA, Khan UH, Shah A, Khan Y, et al. Hookah smoking and lung cancer in the Kashmir valley of the Indian subcontinent. Asian Pac J Cancer Prev. 2011;12(2):519-24.

9. Chaouachi K. Hookah (shisha, narghile) smoking and environmental tobacco smoke (ETS). A critical review of the relevant literature and the public health consequences. International journal of environmental research and public health. 2009;6(2):798-843. https://doi.org/10.3390/ijerph 6020798 PMid:19440416 PMCid:PMC2672364

10. Nasser AMA, Geng Y, Al-Wesabi SA. The Prevalence of Smoking (Cigarette and Waterpipe) among University Students in Some Arab Countries: A Systematic Review. Asian Pac J Cancer Prev. 2020;21(3):583-91. https://doi.org/10.31557/APJCP.2020.21.3.583 PMid:32212782 PMCid:PMC7437327

11. Asgari F, Haghazali M, Heydarian H. Non-communicable diseases risk factors surveillance in Iranian Journal Of Public Health. 2009;38(1):119-122.

12. Ajzen I. Attitudes, traits, and actions: Dispositional prediction ofbehaviorin personalityand social psychology. Advances in experimental social psychology. 20: Elsevier; 1987. p. 1-63. https://doi.org/10.1016/S0065-2601(08)60411-6

13. Alami A, Tavakoly Sany SB, Tehrani H, Lael-Monfared E, Hosseini Z, Jafari $A$. The effect of educational intervention on iron and vitamin $D$ consumption based on the theory of planned behaviour in Iranian adolescent girls: a quasi-experimental study. International Journal of Health Promotion and Education. 2019;57(6):316-31. https://doi.org/10.1080/14635240.2019.1632732

14. Ajzen I, Driver BL. Prediction of leisure participation from behavioral, normative, and control beliefs: An application of the theory of planned behavior. Leisure sciences. 1991;13(3):185-204. https://doi.org/10.1080/01490409109513137

15. Ajzen I. The theory of planned behavior. Organizational behavior and human decision processes. 1991;50(2):179-211. https://doi.org/10.1016/0749-5978(91)90020-T

16. Weglicki LS, Templin TN, Rice VH, Jamil H, Hammad A. Comparison of cigarette and water-pipe smoking by Arab and Non-Arab-American youth. American journal of preventive medicine. 2008;35(4):334-9. https://doi.org/10.1016/j.amepre.2008.06.037 PMid:18675529 PMCid:PMC2575814

17. Gatrad R, Gatrad A, Sheikh A. Hookah smoking. Bmj. 2007;335(7609):20https://doi.org/10.1136/bmj.39227.409641.AD PMid:17615218 PMCid:PMC1910626

18. Martinasek MP, McDermott RJ, Martini L. Waterpipe (hookah) tobacco smoking among youth. Current problems in pediatric and adolescent health care. 2011;41(2):34-57. https://doi.org/10.1016/j.cppeds.2010.10.001 PMid:21232693

19. Heinz AJ, Giedgowd GE, Crane NA, Veilleux JC, Conrad $M$, Braun $A R$, et al. A comprehensive examination of hookah smoking in college students: use patterns and contexts, social norms and attitudes, harm perception, psychological correlates and co-occurring substance use. Addictive behaviors. 2013;38(11):2751-60. https://doi.org/10.1016/j.addbeh.2013.07.009 PMid:23934006

20. Maziak W, Jawad M, Jawad S, Ward KD, Eissenberg T, Asfar T. Interventions for waterpipe smoking cessation. Cochrane Database of Systematic Reviews. 2015(7). https://doi.org/10.1002/14651858.CD005549.pub3 PMid:26228266 PMCid:PMC4838024

21. Neergaard J, Singh P, Job J, Montgomery S. Waterpipe smoking and nicotine exposure: a review of the current evidence. Nicotine \& Tobacco Research. 2007;9(10):987-94. https://doi.org/10.1080/14622200701591591 PMid:17943617 PMCid:PMC3276363

22. Al Ali R, Rastam S, Ibrahim I, Bazzi A, Fayad S, Shihadeh $A L$, et al. A comparative study of systemic carcinogen exposure in waterpipe smokers, cigarette smokers and non-smokers. Tobacco control. 2015;24(2):125-7. https://doi.org/10.1136/tobaccocontrol-2013-051206 PMid:23988862 PMCid:PMC4136964

23. Sutfin EL, McCoy TP, Reboussin BA, Wagoner KG, Spangler $\mathrm{J}$, Wolfson M. Prevalence and correlates of waterpipe tobacco smoking by college students in North Carolina. Drug and alcohol dependence. 2011;115(1-2):131-6. https://doi.org/10.1016/j.drugalcdep.2011.01.018 


\section{PMid:21353750 PMCid:PMC3089695}

24. Joveyni H, Dehdari T, Gohari M. Waterpipe smoking in the male college students: an education intervention using theory of planned behavior. Journal of Research and Health. 2013;3(4):497-503.

25. Sohrabi F. The effectiveness of healthy behavior training program in changing attitude of students towards substance abuse. International Journal of Behavioral Sciences. 2008;2(3):209-20.

26. Mehri A, Abad SSMM, Abad MAMS. The effect of an educational program based on the Theory of Planned Behavior on helmet use among employed motorcyclists. Payesh (Health Monitor). 2012;11(1):13-20.
27. Tabatabaei A, Taghdisi MH, Nakheei N, Balali F. Effect of educational intervention based on the theory of planned behaviour on the physical activities of Kerman Health Center's Staff (2008). Journal of Babol University of Medical Sciences. 2010 Jun 10;12(2):62-9.

28. Hatefnia E, Niknami S, Mahmudi M, Lamyian M. The Effects of "Theory of Planned Behavior" based education on the promotion of mammography performance in employed women. Journal of Birjand University of Medical Sciences. 2010;17(01). 